Article

\title{
In-stream tidal energy resources in macrotidal non-cohesive sediment environments: effect of morphodynamic changes at two bays in the Upper Gulf of California
}

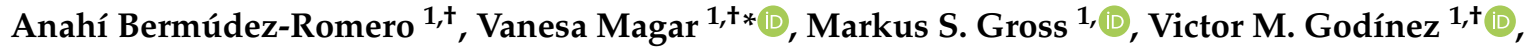 \\ Manuel López-Mariscal ${ }^{1,+} \mathbb{C}$, Julio Candela ${ }^{1,+} \mathbb{\oplus}$ \\ 1 Physical Oceanography Department, CICESE, Carretera Ensenada-Tijuana No. 3918, Zona Playitas, \\ C.P. 22860, Ensenada, Baja California, Mexico; anahi.berom@gmail.com (A.B.-R.); mxcali@cicese.mx (V.M.G.); \\ mgross@cicese.edu.mx (M.S.G.); malope@cicese.mx (M.L.-M.); jcandela@cicese.mx (J.C.) \\ + All authors contributed equally to this work.
}

\begin{abstract}
While many in-steam tidal energy resource studies have been carried out globally, very few studies have assessed the effect of seabed changes on tidal energy resources. For coastal regions in particular, where the seabed is generally more mobile than in deep waters, bathymetric evolution could have a significant effect on tidal energy production. Here two high-resolution models, one purely hydrodynamic and one morphodynamic, are used to analyse the potential effect of natural morphodynamic evolution on tidal energy resources at two macro-tidal sandy bays, Adaír Bay and San Jorge Bay, in the Upper Gulf of California, Mexico. The high-resolution models are validated using a low-resolution model and ADCP observations to assess the agreement between model predictions and observations of tides at three ADCP moorings within the domain of interest. The models' skill is evaluated using several error statistics such as the mean relative error, the root mean square error (RMSE), and the correlation coefficient. It was found that the regions with the largest bed changes, and also the largest renewable energy resources, were near the shore. Moreover, the results indicated a good correlation between a) regions with the most significant depth changes, and b) the regions where the difference in annual energy production with and without depth change was largest. Finally, the morphodynamic model was run for two years, and the evolution of a zonal profile (in the west-east direction) off the coast at the southeastern corner of Adaír Bay was inspected. This profile evolved towards a featureless equilibrium profile, in good agreement with the morphological classification for macro-tidal sandy environments and with the model assumptions. But most importantly, this natural evolution would not be detrimental to tidal energy exploitation at the site.
\end{abstract}

Keywords: In-Stream Tidal Energy Resources; Macro-Tidal Environments; Marine Renewable Energy; Gulf of California

\section{Introduction}

In the Gulf of California (GC), a marginal sea located in the northwest Mexican coast (See Figure 1), many studies (both numerical and observational) have described different oceanographic phenomena and their dynamics, for example, trapped coastal waves, tides and residual currents, coastal upwelling, or gyre evolution and tidal mixing, to name but a few [1-4]. Tides in the GC have also been characterised as a form of renewable energy, for the past twenty years [2,5]. The first analysis assessing the effects of the choice of bathymetry on renewable energy resources in the GC was presented in [6], using the Infiernillo Channel, the strait between Tiburón Island and Mexico's mainland, as case study. The bathymetries used were the GEBCO08 and the GEBCO14 bathymetries, which at the time of that study could be downloaded from https://www.gebco.net/, and a third 
bathymetry generated with in-situ measurements by Lancín [7], which was corrected and digitized in-house. In the GEBCO bathymetries there were some regions with evident bathymetric inaccuracies; the observed outliers were removed before interpolating the bathymetric data to the model grid. Even with these corrections, Magar [6] showed the choice of bathymetry has remarkable effects on the monthly tidal power density (TPD) maps at the site, not only in relation to the magnitude of the $T P D$, but also in relation to the locations of maximum TPD predicted by the models. Additional data from in-situ measurements in the Infiernillo Channel could not be obtained after that initial analysis of Magar [6], however, because negotiations with the Channel owners resulted in a mutual agreement to support community-led renewable energy projects on land, rather than at sea. Therefore, in-situ measurements and regional modelling efforts were relocated to other potential tidal energy exploitation sites within the GC.

Three ADCP moorings were installed between 2017 and 2018 in San Jorge Bay and Adaír Bay, the Northeastern Bays next to the port of Puerto Peñasco. These bays, shown in Fig. 1, are the focus of the analysis presented here, and preliminary model validations using those moorings were discussed by Bermúdez-Romero et al. [8]. This site was chosen not only for the reasons discussed above, but also because it has some characteristics that turn it into a promising site for in-stream tidal energy projects. Firstly, it is well known that although coastal straits are potential in-stream tidal energy sites, coastal headlands can also be suitable, because of the local flow accelerations caused by the headland. The 10MW tidal array planned in the Ramsey Sound, for example [9], is both off a headland, St David's Head, and within St Georges' Channel, that is, between an island, The Republic of Ireland, and Wales, on the UK's mainland. Although there are no islands just in front of Puerto Peñasco, on its western side the ocean waters of the Upper Gulf of California are constricted between the two headlands delimiting the entrance to Adaír Bay. Secondly, near the port of Puerto Peñasco the tidal range is of more than six meters, and it is expected that this will cause flow speeds between slack waters that could be sufficiently large for in-stream tidal array developments. Thirdly, the port of Puerto Peñasco is a port with important commercial activity and, therefore, the area has large energy demands, and it is well connected to the power transmission lines, which is considered to be an almost essential feature for commercial renewable energy development [10]. Finally, the water depth in the region can be of $60 \mathrm{~m}$ or larger, and thus devices operating at such water depths can be installed here. It is important to note that there are no bathymetric surveys with finer resolutions than the GEBCO2014 one available here. However, the regions where the GEBCO2014 bathymetry has significant errors have been masked. Outliers in the regions where we do have bathymetries from the Ministry of Defense (SEMAR) to compare the GEBCO2014 with have been removed. However, as the SEMAR surveys have been done more than 10 years ago and their resolution is also of the order of $900 \mathrm{~m}$, it was deduced that, in general, the SEMAR surveys were not necessarily better that GEBCO2014 for the purposes of this study. This is so, in particular, because the SEMAR surveys do not have measurements in the area where GEBCO2014 proved to be most unreliable. Also, more recent versions of the GEBCO bathymetries have improved in other regions of the globe but not in the study area, and so the choice of GEBCO2014 is justified. Regional models are reliable tools that help reproduce instantaneous and mean current velocity fields. They can be used, for example, to solve knowledge gaps regarding the potential effects of seabed evolution on tidal power density and tidal energy extraction. Recently, Chatzirodou et al. [11] found that in-stream energy farms can have a significant impact on local hydrodynamics and seabed changes and, thus, influence the formation and evolution of nearby sandbanks. However, sandbanks, as other bedforms, evolve in response to natural driving forces too. Therefore, one may consider a baseline study, focusing on the effect of natural seabed evolution on the theoretical in-stream energy resources, that is, before the tidal energy converters are installed, and assess whether this evolution impacts significantly the available in-stream energy resources. This is a different approach to that by Chatzirodou et al. [11] , or by Robins et al. [12], who have assessed the effects of tidal arrays on the evolution of nearby sandbanks, and assess whether the array has an "acceptable" effect. Robins et al. [12] define "acceptable change" as that which is below 
the natural levels of inter-seasonal and inter-annual variability of tidally-induced and wave-induced local bed shear stress; but they do not analyse how natural variability of bed shear stress and seabed evolution affects the available resources. Robins et al. [12] use a hydrodynamic model that has a variable resolution grid, from a coarsest $2000 \mathrm{~m}$ resolution, near the western part of the Irish Sea, to a finest 15-50 m resolution at the Langdon site, on the western coast of the Isle of Anglesey. The model is forced by waves and tides and the seabed evolves in time for different seabed sediment fractions, which are then added together to obtain the overall seabed evolution.

As inferred by the studies described above, many authors have assessed morphodynamic changes in natural environments for renewable energy applications in relation to the potential environmental impacts of tidal array developments, but no studies have quantified the sensitivity of the energy resources to natural seabed changes, using regional modelling tools. For example, one may hypothesise that small changes in the morphology can lead to important changes in TPD or AEP, and this may prove to be important for in-stream tidal energy plant planning. It is, also, important to highlight that the analysis of Robins et al. [12] includes waves and tides because they are both important off the western open coast of Anglesey, facing the Atlantic ocean. In contrast, for the two bays considered here it is not necessary to include the effect of waves in a first analysis, because the GC is a marginal sea and the Adaír and San Jorge bays are at the head of this marginal sea, thus the effect of swell may be neglected. However, under strong winds there may be storm waves in the region as well as a wind-driven circulation that, as demonstrated in [13], can be significant. However, in this study climatologically-average conditions are assumed, and thus, the effects of the wave field and the wind-induced circulation on the annual tidal energy resources may be omitted. Also, because the objective of this work is not to evaluate the impacts of tidal energy devices on the environment, but to assess the natural morphodynamic evolution effects on the suitability of a particular site for tidal energy resource exploitation, it is not necessary either to introduce a representation of the devices within the numerical model, although that may be an obvious extension to the work presented. Finally, it is worth mentioning the work of Haverson et al. [9,14] who, like Robins et al. [12], have also assessed the environmental effects of tidal arrays at sites that have been earmarked for tidal array installations. The fact that the effects of the tidal devices on the environment have to be captured, also means that the local resolution of the model mesh has to be of the order of 5 to 10 meters in some places. However, in order to assess the natural variability of the seabed and its effect on the theoretical energy resources, a mesh resolution of the order of $100 \mathrm{~m}$ is deemed to be sufficient, based on the protocols established by Legrand [15].

In this paper, we set up two multi-domain models with high resolution in the area of interest. The models have the same open-boundary forcings at the mouth of the GC and same initial bathymetry, but one of them is only hydrodynamic and the other one is a morphodynamic model. The high-resolution domain covers two macro-tidal bays on the northeastern side of the Upper GC: Adaír Bay and San Jorge Bay (See Figure 1). Both models are validated against the ADCP observations. The flow velocity fields, the mean annual tidal power density (TPD) and the annual energy production (AEP) are determined over a climatologically-typical year. In addition, the model is run for a second year, but this longer simulation period is used mostly to assess that the seabed is evolving as one would expect, based on the forcings included in the model.

The paper is organised as follows. In Sec. 2, the model equations and the initial and boundary conditions are described, together with the calibration parameters and statistical measures used for the calibration and validation of the models against the ADCP observations. In Sec. 3, the mean peak flow during spring tides, $U_{S T M}$, the annual average of the tidal power density $(T P D)$, and the annual energy production $(A E P)$ maps predicted by the hydrodynamic and morphodynamic models are presented and discussed. Then, the implications of natural seabed changes for tidal energy resource exploitation in the area are analysed, in particular in the regions with the largest $U_{S T M}$ and TPD values. The natural evolution of the seabed is assessed over a two-year period, to show that the tendencies 


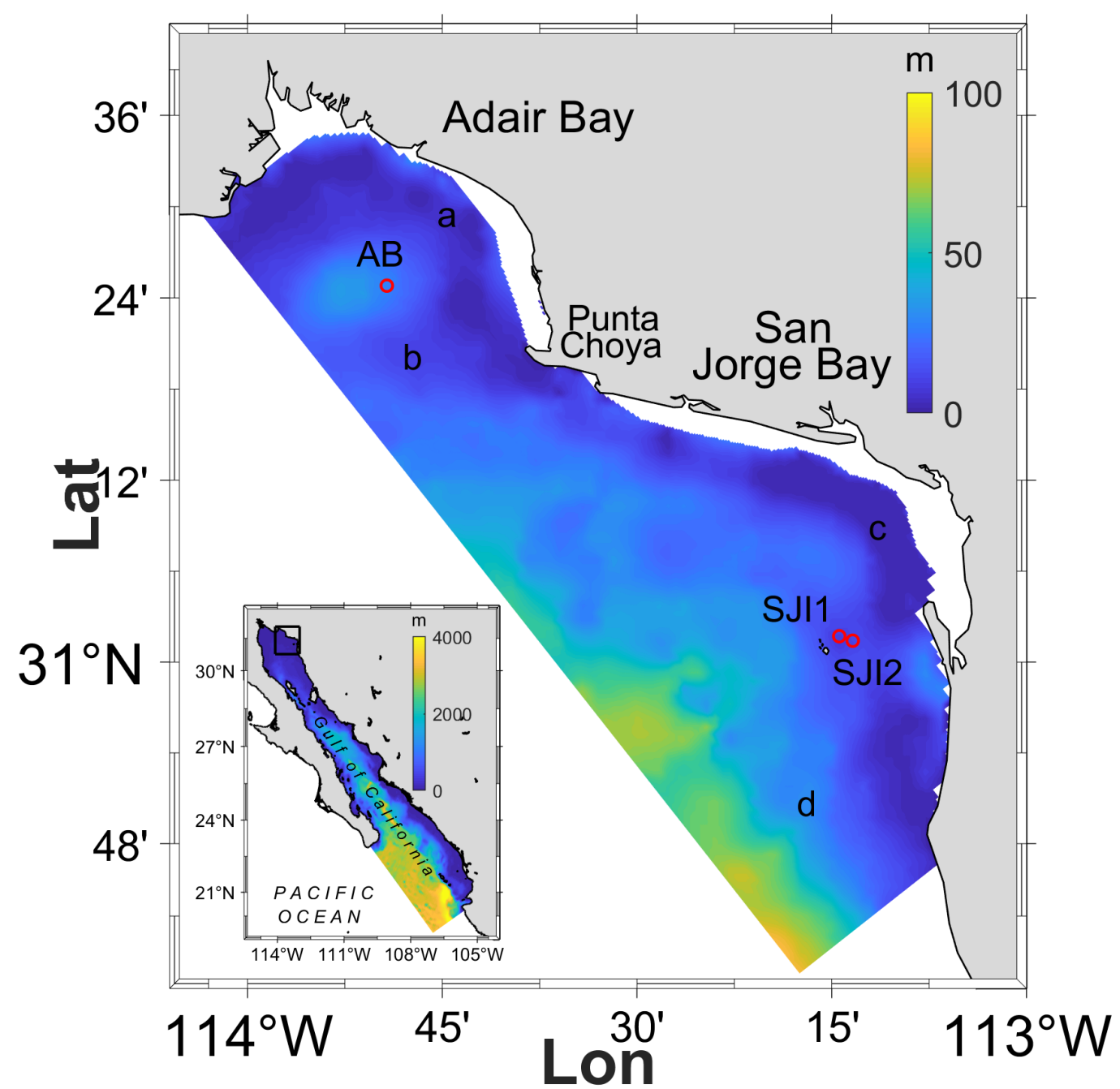

Figure 1. Bathymetry of the study area. The bathymetry is the GEBCO2014 bathymetry with a mask in some coastal regions. SJI1, SJI2, and AB are the locations of the ADCPs used for calibration and verification of the numerical model. The indices $a, b, c$ and $d$ indicate locations used for the in-depth energy resource analysis.

predicted by the model are the same over a two-year period than over one year, indicating that the patterns observed in the one-year simulation are maintained over longer periods of time.

\section{Materials and Methods}

\subsection{Hydrodynamic and Morphodynamic Models: Description}

The numerical simulations were carried out with Delft3D-Flow using the domain decomposition method. Delft3D-Flow solves the incompressible Navier-Stokes equations under the shallow water and the Boussinesq approximations to simulate shallow water flows [16], coupled with an advection-diffusion equation and the Exner equation for sediment transport and morphodynamic evolution, respectively. In 3D simulations, The default version of Delft3D uses curvilinear coordinates in the horizontal dimensions, and $\sigma$, terrain-following coordinates in the vertical dimension [17]. In this work the two-dimensional. vertically integrated model is implemented, under the assumption that tides are forced by the Pacific Ocean at the mouth of the GC. As mentioned in [13], this is a reasonable assumption. 
The vertically-integrated system of equations consists of two momentum conservation equations for the velocity components $(U, V)$, a conservation equation for the hydrostatic pressure $P$, and the continuity (mass conservation) equation for the water level $\zeta$ :

$$
\begin{gathered}
\frac{\partial U}{\partial t}+U \frac{\partial U}{\partial x}+V \frac{\partial U}{\partial y}+\frac{\omega}{\zeta+d} \frac{\partial U}{\partial \sigma}-f V=-\frac{1}{\rho_{0}} \frac{\partial P}{\partial x}+F_{x}+M_{x}+\nabla \cdot\left(D_{H} \nabla U\right)+\tau_{s x}-\tau_{b x} \\
\frac{\partial V}{\partial t}+U \frac{\partial V}{\partial x}+V \frac{\partial V}{\partial y}+\frac{\omega}{\zeta+d} \frac{\partial V}{\partial \sigma}+f U=-\frac{1}{\rho_{0}} \frac{\partial P}{\partial y}+F_{y}+M_{y}+\nabla \cdot\left(D_{H} \nabla V\right)+\tau_{s y}-\tau_{b y}, \\
P=g \rho_{0}(\zeta+d), \text { and } \\
\frac{\partial \zeta}{\partial t}+\frac{\partial[(\zeta+d) U]}{\partial x}+\frac{\partial[(\zeta+d) V]}{\partial y}=0,
\end{gathered}
$$

where $\zeta$ is measured from the reference level corresponding to mean sea level (MSL) and $d$ is the water depth from MSL, defined as positive downwards. The terms $\left(F_{x}, F_{y}\right)$ are the components of a vector force representing the unbalance of the horizontal Reynolds stresses; the Reynolds stresses are modelled using the eddy viscosity concept introduced by [18]. The forces $\left(F_{x}, F_{y}\right)$ are necessary because, although the model is capable of resolving the turbulent scales, usually the hydrodynamic grids are too coarse to resolve the fluctuations, and therefore the basic equations are Reynolds-averaged, introducing so-called Reynolds stresses. The Reynolds stresses are related to the Reynolds-averaged flow quantities through a turbulence closure formulation. $\left(M_{x}, M_{y}\right)$ are the external forcing and source/sink terms due, for instance, to discharge or withdrawal of water, water-structure interactions, or wave stresses; $D_{H}$ is the depth-averaged horizontal turbulent eddy viscosity, and $\tau_{s}-\tau_{b}$ represents the difference between the surface and the bottom shear stresses, respectively. The vertical velocity $\omega$ is defined at the $\sigma$-surfaces, and is the vertical velocity relative to the moving $\sigma$-plane. It may be associated to the velocity of the upwelling and downwelling motions [19].

As discussed in Sec. 1, the bathymetry chosen for the simulations was the General Bathymetric Chart of the Oceans (GEBCO2014). GEBCO2014 has a spatial resolution of 30 arc-seconds, equivalent to approximately $900 \mathrm{~m}$ (see Figure 1); some outliers were removed and a mask was applied in regions very close to the shore where GEBCO2014 proved to be inaccurate, for example in the coastal lagoons around the shore of San Jorge Bay. However, since the focus of this work is on the offshore regions around the coastal shoals of Adaír Bay and the areas in the two bays with water depths of $10 \mathrm{~m}$ or more, this masking does not affect the results presented here. Finally, the bathymetry was interpolated into the model grid using cell averaging, triangular interpolation, or internal diffusion, depending on the number of bathymetric data points within the grid cells.

The hydrodynamic domain decomposition model, named as GC_MD, is a vertically-averaged model with three sub-domains: a coarse domain with a spatial resolution of $6480 \mathrm{~m}$ covering the western approach (where it connects to the Pacific Ocean) and the deep parts of the GC; an intermediate domain with a spatial resolution of $2160 \mathrm{~m}$ in the coastal regions and the north part of the Gulf; and an inner domain with a resolution of $240 \mathrm{~m}$ covering Adaír Bay and San Jorge Bay, located in the Northeastern part of the Gulf. The morphodynamic model, named as GC_MD mor, is based on the same domains, same hydrodynamic forcings and same bathymetry as GC_MD, but it includes sediment transport and morphodynamics.

The GC_MD and GC_MD mor models were forced at the mouth of the Pacific Ocean with 13 principal tidal harmonics (M2, S2, N2, K2, K1, O1, P1, Q1, MF, MM, M4, MS4, MN4) from the TPXO8.1 model, a Global Inverse Tidal Model [20,21]. In GC_MD mor, the sediment transport and morphodynamics computations were carried out assuming that the seabed is mostly composed of non-cohesive sediments with a median sediment diameter $\mathrm{D}_{50}$ of $200 \mu \mathrm{m}$, corresponding to a sandy seafloor; a specific density of $2650 \mathrm{~kg} \mathrm{~m}^{-3}$; a dry bed density of $1600 \mathrm{~kg} \mathrm{~m}^{-3}$; and an initial sediment layer thickness of $5 \mathrm{~m}$. Since the sediment in the eastern side of the Upper GC varies from medium to fine sand [22], these assumptions are adequate in this region. 
Van Rijn's model for sediment bedload and suspended load transport is used in the computations [23]. In this approach, the sediment concentration $C$ of the single sediment fraction [in $\mathrm{kg} \mathrm{m}^{-3}$ ], satisfies a three-dimensional advection-diffusion equation of the form:

$$
\begin{array}{r}
\frac{\partial C}{\partial t}+\frac{\partial u C}{\partial x}+\frac{\partial v C}{\partial y}+\frac{\partial\left(w-w_{s}\right) C}{\partial z}= \\
\frac{\partial}{\partial x}\left[\epsilon_{s, x} \frac{\partial C}{\partial x}\right]+\frac{\partial}{\partial y}\left[\epsilon_{s, y} \frac{\partial C}{\partial y}\right]+\frac{\partial}{\partial z}\left[\epsilon_{s, z} \frac{\partial C}{\partial z}\right]+S
\end{array}
$$

where $(u, v, w)$ as the flow velocity components $\left[\mathrm{m} \mathrm{s}^{-1}\right], w_{s}$ the settling velocity $[\mathrm{m} / \mathrm{s}], \epsilon_{s}=$ $\left(\epsilon_{s, x}, \epsilon_{s, y}, \epsilon_{s, z}\right)$ the sediment diffusivity $\left[\mathrm{m}^{2} \mathrm{~s}^{-1}\right]$, and $S$ the sediment source/sink terms $\left[\mathrm{kg} \mathrm{m}^{-3} \mathrm{~s}^{-1}\right]$. The bottom boundary condition for non-cohesive sediments is a balance between the erosion $(E)$ and deposition $(D)$ flux terms, which in turn depend on the settling and diffusion processes at a bottom reference bed level $z=z_{b}$ :

$$
E-D=\epsilon_{s, z} \frac{\partial C}{\partial z}+w_{s} C
$$

As there are neither estuaries nor other sources of sediment discharge in the area of interest, the source/sink terms in Eqn. 6 are directly linked to $E-D$, as defined in Eqn. 7.

\subsection{Calibration of the Hydrodynamic Model}

Three Acoustic Doppler Current Profilers (ADCPs) were installed to measure the flow velocity, two in San Jorge Island (SJI1 and SJI2), located south of San Jorge Bay, and one in Adaír Bay (AB). SJI1 was operational from 5 June 2017 to 26 November 2017 ( SJI1 17), and from 22 June 2018 to 6 November $2018\left(\right.$ SJI1 $\left._{18}\right)$. SJI2 was operational from 21 June 2018 to 21 November 2018. AB was operational from 14 December 2018 to 14 May 2019. Here are some additional characteristics of the ADCP mooring sites:

1. ISJ1: ISJ $1_{17}$ is used for model calibration and ISJ $1_{18}$ for model validation. This mooring was installed at an average water depth of $16 \mathrm{~m}$. The tidal range here is $6.5 \mathrm{~m}$ on average.

2. ISJ2: This mooring was at an average water depth of $22 \mathrm{~m}$, The tidal range here is $6.3 \mathrm{~m}$, .

3. AB: Located in Adaír Bay at an average water depth of $17 \mathrm{~m}$. The tidal range here is $7.3 \mathrm{~m}$ on average.

The parameters used to calibrate the model were the reflection parameter, the horizontal viscosity, and the friction coefficient $C_{f}\left[\mathrm{~m}^{1 / 2} \mathrm{~s}^{-1}\right]$, based on Chézy's formulation. The sensitivity of the model to changes of the reflection coefficient and the viscosity was very small, so the default values was selected. Table 1 shows the values of $C_{f}$ used for model calibration, together with the relative error and the root mean square error between model and observations. Based on the results, the final $C_{f}$ was taken as $45 \mathrm{~m}^{1 / 2} \mathrm{~s}^{-1}$. This is expected, based on results shown by Baston et al. [24].

After calibration, the GC_MD model was validated with the moorings at SJI1 $17, \mathrm{SJI}_{18}, \mathrm{SJI2}$ and $\mathrm{AB}$ (see Table 2). GC_MD mor was validated with SJI1 17 only. The calibrations and validations of the models were assessed by determining the agreement between model $X=U_{\text {mod }}$ and ADCP data $Y=U_{o b s}$, for the reconstructed tidal signal. An example of the reconstructed tidal signals is shown in Fig. 2, for the GC_MD mor model, and the data obtained with the ADCP in Adaír Bay.

The agreement between model and observations was assessed using the Pearson correlation coefficient, $\rho_{X, Y}[-]$ (non-dimensional), defined as [25]:

$$
\rho_{X, Y}=\frac{\operatorname{cov}(X, Y)}{\sigma_{X} \sigma_{Y}}=\operatorname{Corr}_{U}
$$




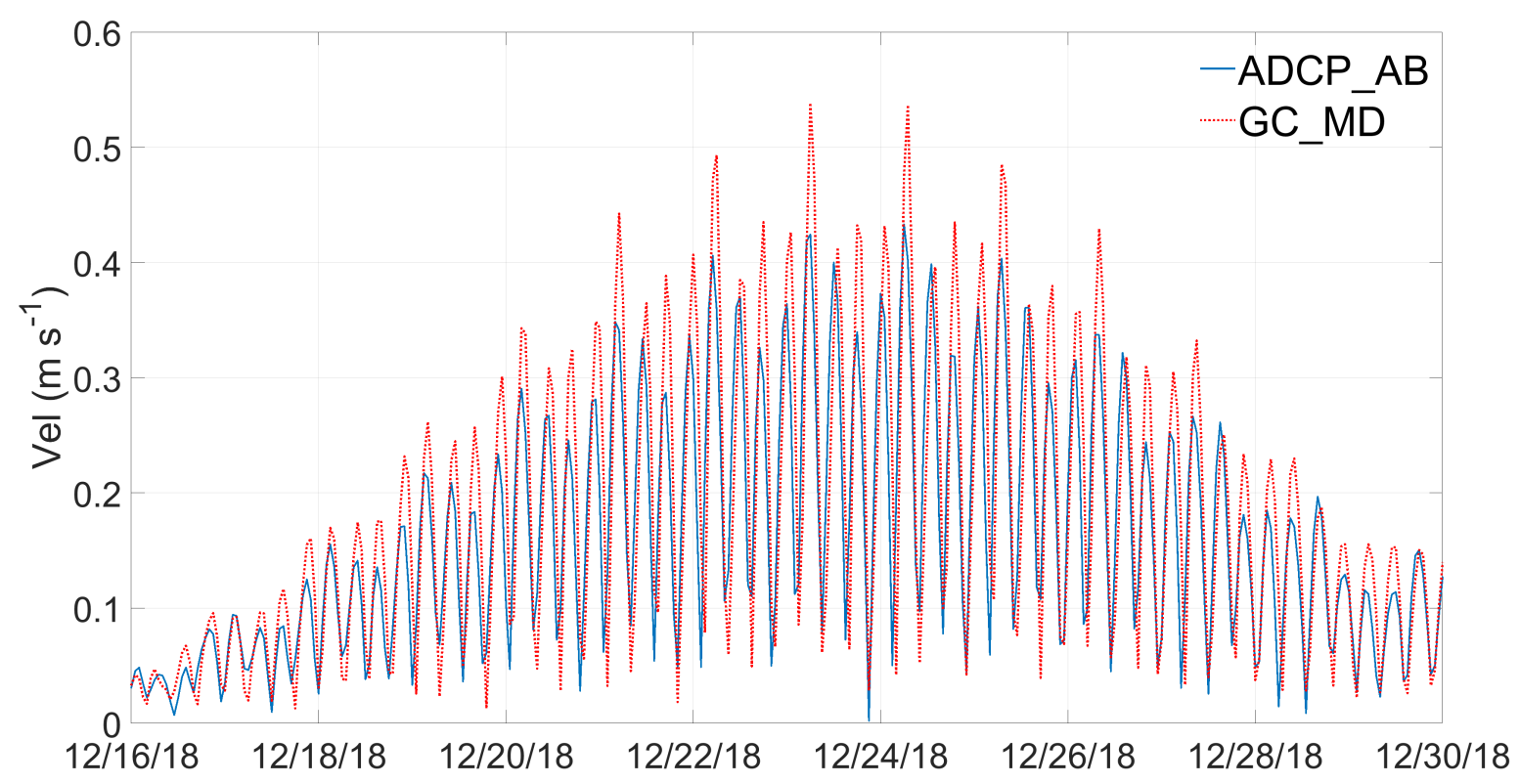

Figure 2. Validation of flow speed, for ADCP measurements and GC_MD model outputs at AB.

where cov is the covariance between the two time series, and $\sigma_{X}$ and $\sigma_{Y}$ the standard deviations of $X$ and $Y$, respectively; the absolute relative error, $R E_{U}[\%]$,

$$
R E_{U}=\left\|\frac{\bar{U}_{o b s}-\bar{U}_{m o d}}{\bar{U}_{o b s}}\right\| \times 100 ;
$$

and the Root Mean Square Error, $R M S E_{U},\left[\mathrm{~m} \mathrm{~s}^{-1}\right]$ :

$$
\operatorname{RMSE}_{U}=\sqrt{\frac{1}{N} \sum_{i=1}^{N}\left(U_{m o d, i}-U_{o b s, i}\right)^{2}}
$$

of the modelled and the observed yearly-mean speeds. The time interval used for the model-measurement intercomparisons was of $30 \mathrm{~min}$ at the SJI1 $1_{17}, \mathrm{SJI}_{18}$ and SJI2 moorings, and 60 min at the $\mathrm{AB}$ mooring.

Table 1. Model calibration with $\mathrm{SJI}_{17}$ 06/05/17 to 11/26/17

\begin{tabular}{|c|c|c|c|c|}
\hline Model & $C_{f}$ & Corr $_{U}$ & $R M S E_{U}$ & $R E_{U}$ \\
\hline GC_MD & 65 & 0.9390 & 0.1381 & $52 \%$ \\
GC_MD & 45 & 0.9294 & 0.0828 & $26 \%$ \\
\hline
\end{tabular}

\subsection{Validation of $G C \_M D$ and $G C \_M D_{\text {mor }}$}

We used the ADCP moorings ISJ1, ISJ2 and AB, introduced in the previous section, to validate the results obtained with the models. Table 2 summarises the results of these validations for the yearly-mean speed, $\bar{U}$, obtained from the GC_MD model speed predictions and vertically-averaged speed observations.

Overall, the correlation coefficient, the RE and the RMSE values obtained in the modelled-observed speed comparisons were acceptable. SJI2 was the location with the smallest correlation, but a relatively large RMSE of $0.115 \mathrm{~m} / \mathrm{s}$. This large RMSE for the flow speeds causes significant errors for the TPD and the AEP validations at this location. We obtain the best agreement 
Table 2. Validation variables at the ADCP moorings, for GC_MD (first 4 rows) and GC_MD mor (last row).

\begin{tabular}{c|c|c|c|c|c|c|}
\hline Model & Mooring & Period & $\bar{U}$ mod/adcp & Corr $_{U}$ & $R E_{U}$ & $R M S E_{U}$ \\
\hline GC_MD & SJI1 $_{17}$ & $06 / 05-11 / 26,2017$ & $0.23 / 0.22$ & 0.8766 & $20 \%$ & 0.0685 \\
GC_MD & SJI1 $_{18}$ & $06 / 22-11 / 06,2018$ & $0.23 / 0.19$ & 0.8880 & $21 \%$ & 0.0692 \\
GC_MD & SJI2 & $06 / 21-11 / 21,2018$ & $0.22 / 0.23$ & 0.7072 & $1.6 \%$ & 0.1150 \\
AB & $12 / 14 / 18-05 / 14 / 19$ & $0.16 / 0.15$ & 0.8681 & $6.1 \%$ & 0.0567 & \\
\hline GC_MD & SJI1 17 & $06 / 05 / 17$ to $11 / 26 / 17$ & $0.29 / 0.22$ & 0.8815 & $9 \%$ & 0.2938 \\
\hline
\end{tabular}

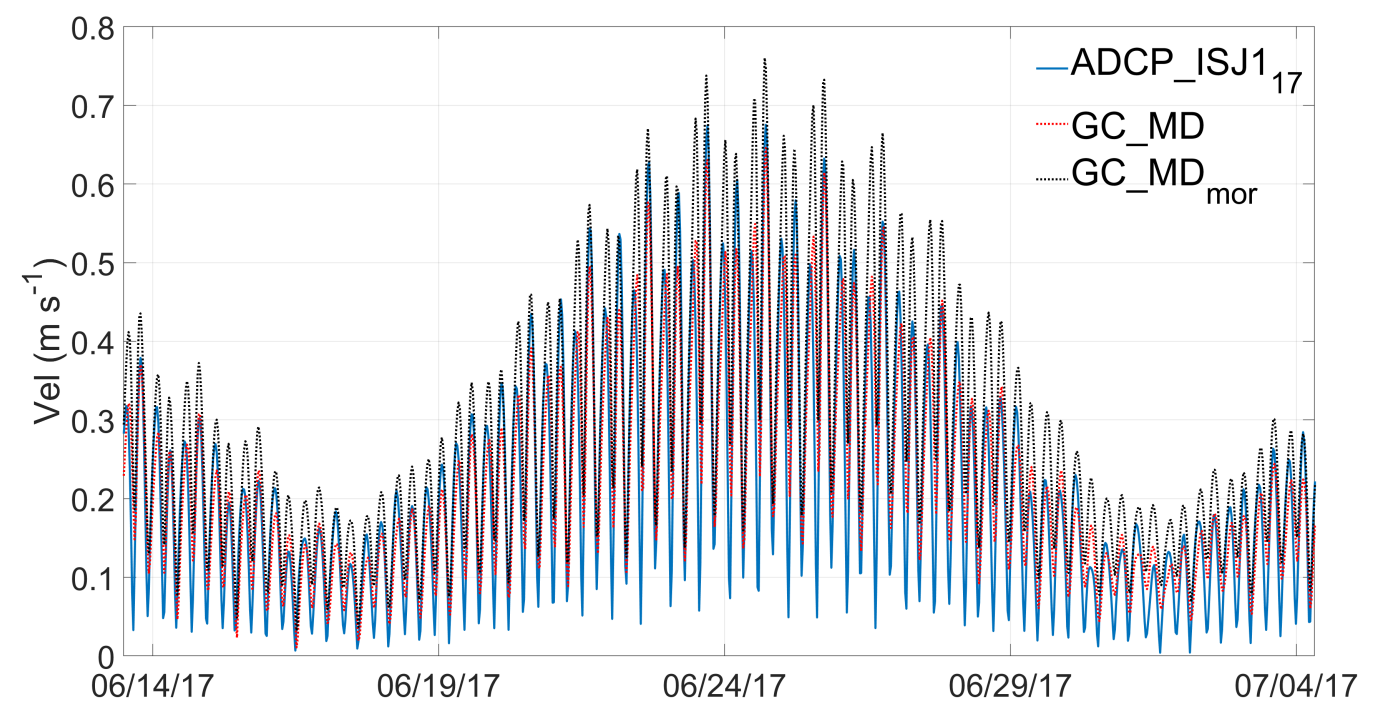

Figure 3. Reconstructed tidal signal for the ADCP measurements (blue), the GC_MD model (dashed red), and the GC_MD mor model, for a fortnight period at the ISJ1 mooring.

between the GC_MD and the ADCP reconstructed tidal speed time series at the AB mooring, shown in Fig. 2. However, in some tidal cycles, GC_MD seems to overestimate the flow speed.

To validate the morphodynamic model GC_MD mor, we used the depth-averaged reconstructed tidal ADCP measurements taken at the $\mathrm{SJI}_{17}$ mooring, and the corresponding depth-averaged, reconstructed tidal signal predicted by GC_MD $\mathrm{D}_{\text {mor }}$. We found a good correlation of 0.88 (see Table 2) and an excellent relative error of $9 \%$ between model and measured data, but in Fig. 3 we see that the GC_MD $D_{\text {mor }}$ model overestimates the flow speeds at the ADCP moorings. Table 2 shows the value of the $R M S E_{U}$, which is quite high, considering the mean values of the velocity field at this location, also shown in Table 2.

\section{Results and Discussion}

We ran a one-year simulation of the GC_MD and GC_MD mor with the calibrated parameters, to map and analyse the yearly-averaged spring tidal speed maxima, $U_{S T M}$, the yearly-averaged Tidal Power Density, TPD, and the Annual Energy Production, AEP. The instantaneous TPD, TPD ${ }_{i}$, is defined as:

$$
T P D_{i}=\frac{1}{2} \rho U_{i}^{3},
$$

with $U_{i}$ being the instantaneous speed. Its mean is defined simply as

$$
T P D=\frac{1}{N} \sum_{i=1}^{N} T P D_{i}
$$



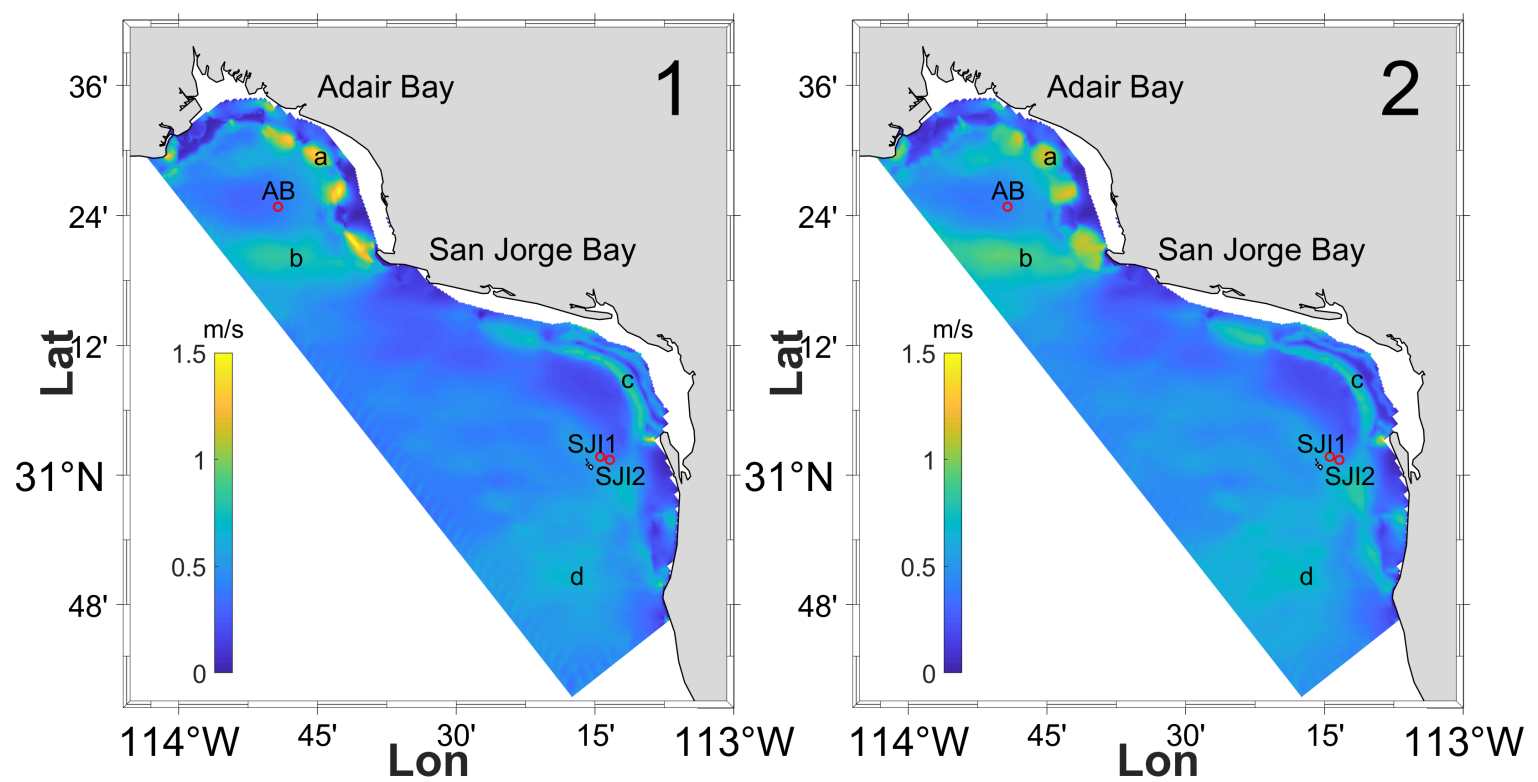

Figure 4. Yearly average of spring tidal maxima flows, $U_{S T M}$, obtained with the CG_MD (left, 1$)$ and the GC_MD mor (right, 2) models.

and the $A E P$ is defined as:

$$
A E P=\sum_{i=1}^{N} T P D_{i}
$$

Here $N$ is the total number of hourly data in the simulated year, or the number of times when $T P D_{i}$ is above the threshold value of $50 \mathrm{~W} \mathrm{~m}^{-2}$, depending on the variable used. This technical TPD threshold corresponds to a low-speed threshold of $0.46 \mathrm{~m} \mathrm{~s}^{-1}$, typical of most tidal energy devices, as discussed in [26].

The mean spring tidal speed maxima, $U_{S T M}$, is computed by identifying the maximum flow speed in spring tides, which for the year of simulation gives 26 maxima, and then computing the mean of those values.

\subsection{Analysis of $U_{S T M}$}

Figure 4 shows the yearly mean of the spring tidal maxima flows, $U_{S T M}$, for the GC_MD (Subplot 1) and the GC_MD $D_{\text {mor }}$ models (Subplot 2). We obtained the most significant $U_{S T M}$ values in the nearshore of Adaír Bay, where we have a series of shoals. In these regions, $U_{S T M}$ reaches values above $1 \mathrm{~m} \mathrm{~s}^{-1}$ and of up to $1.5 \mathrm{~m} \mathrm{~s}^{-1}$, which may be suitable for some shallow-water, in-stream tidal energy systems.

\subsection{Analysis of TPD}

Figure 5 shows the yearly mean TPD obtained for the GC_MD model (Subplot 1 ) and the morphodynamic model GC_MD mor model (Subplot 2) over the simulation year. We found maximum TPD values in the nearshore region of Adaír Bay, of up to $200 \mathrm{~W} / \mathrm{m}^{2}$. These regions are, consistently, in the same locations of the domain in the GC_MD and the GC_MD mor models. However, in GC_MD $D_{\text {mor }}$, the regions with high TPD are spread over larger areas. Such TPD values are significantly lower than those reported for the seven US sites analysed in the Tidal In-Stream Energy Conservation (TISEC) program [27]. The TISEC site with lowest power density was Head Harbour Passage (New Brunswick), with a TPD of $940 \mathrm{~W} / \mathrm{m}^{2}$. In contrast, the Minas Passage in Nova Scotia has a TPD of $4.5 \mathrm{~kW} / \mathrm{m}^{2}$, i.e more that 20 times larger than in our study site. Sites with lower TPD will have higher construction 

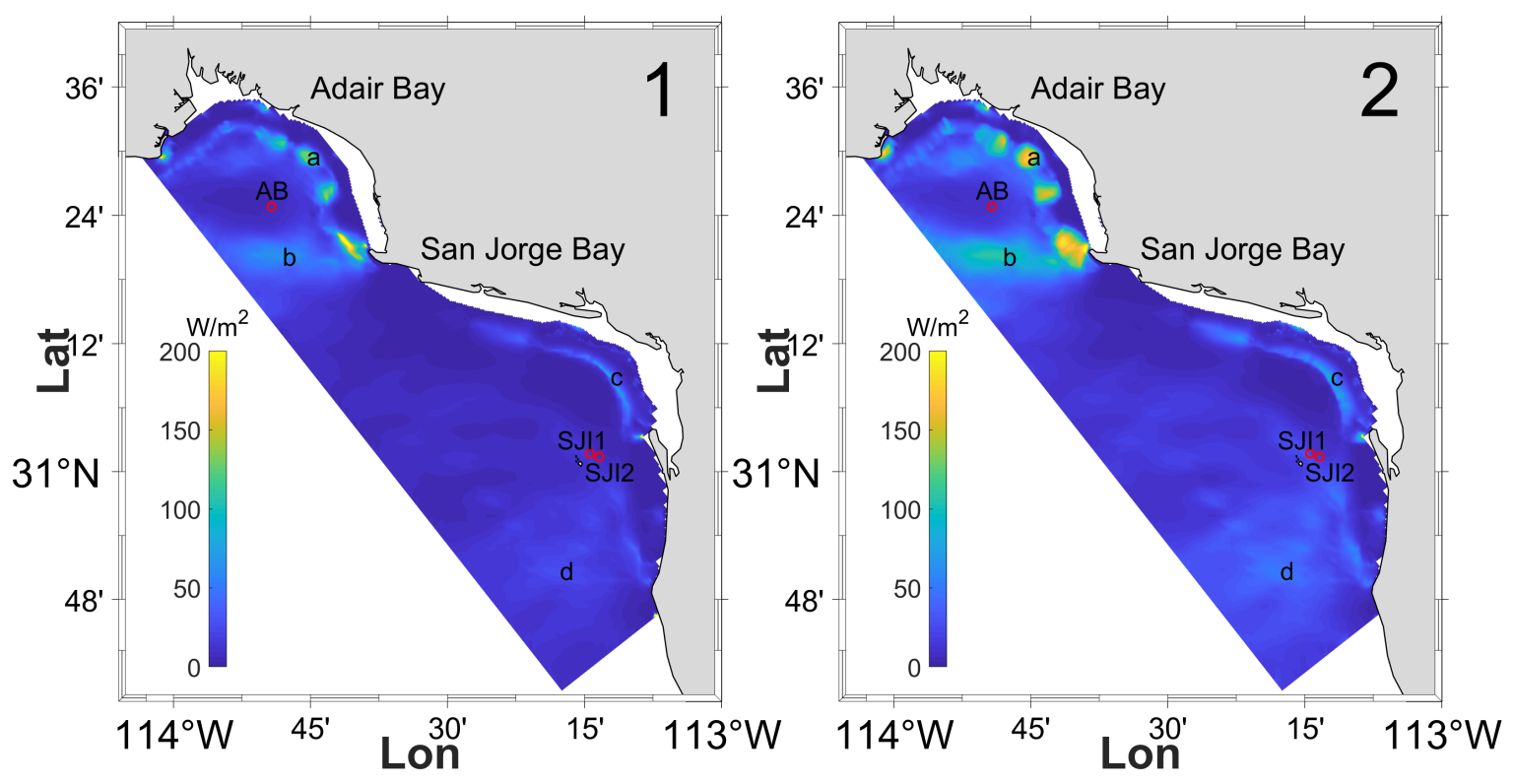

Figure 5. Yearly averaged TPD obtained with the GC_MD (left, Subplot 1) and the GC_MD mor (right, Subplot 2) models.

costs. Small scale also increases the costs by a factor of three [27], and this applies to pilot sites. Despite these drawbacks, this site could still be used as a test site for some devices.

\subsection{Analysis of AEP}

Figure 6 shows the AEP maps, with contours of $500 \mathrm{kWh} \mathrm{m}^{-2}$ delimiting high-energy regions in Adaír bay; these contours can be seen in the results for both the GC_MD (subplot 1a) and the GC_MD mor models (subplot 2a). When using the GC_MD mor model (subplot 2a), i.e., when the seabed evolves in time, these high-energy regions cover a much larger area. In particular, the region with maxima $A E P$ located at the southeastern boundary of Adaír Bay extends further to the west in the

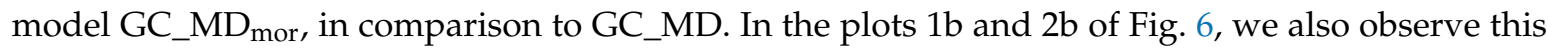
spreading of what we may call good sites for tidal energy exploitation, as measured by the spread of the $200 \mathrm{kWh} \mathrm{m}^{-2}$ contour, extending in San Jorge Bay in GC_MD $\mathrm{Mor}_{\text {, }}$ and an increase from 200 to $400 \mathrm{kWh} \mathrm{m}^{-2}$ in the locations of large AEP. However, in San Jorge Bay these regions are significantly smaller than in Adaír Bay, for both the GC_MD (plot 1a vs plot 1b in Fig. 6) and the GC_MD mor models (plot $2 a$ vs plot $2 b$ in Fig. 6). We can identify the sites with the best renewable energy resources from the AEP maps. Most importantly, however, is the fact that the plots in Fig. 6 show the impact of natural seabed evolution on areas with exploitable renewable energy resources. Indeed, within a year the size of such regions has more than doubled in Adaír Bay, a reassuring result for any would-be tidal energy developer interested in implementing a tidal energy demonstration plant in the region.

\subsection{Technical constraints}

Some devices, such as Flumill[28] for deployments in waters as shallow as $10 \mathrm{~m}$ and up to $50 \mathrm{~m}$ deep, or Minesto [29] for deep water deployments, can operate at the low tidal stream speeds of around $1 \mathrm{~m} \mathrm{~s}^{-1}$ that are found in some locations in the Adaír and San Jorge Bays (as shown in Fig. 4). Another technical constraint to consider is the cut-in speed. Most commercially viable technologies require cut-in tidal speeds of around $0.5 \mathrm{~m} \mathrm{~s}^{-1}$ before they start generating any power from the flow; this cut-in speed corresponds to $T P D=50 \mathrm{~W} \mathrm{~m}^{-2}$. In Figures 7 and 8 , we only consider TPD values of $50 \mathrm{~W} \mathrm{~m}^{-2}$ or above, defined as $T P D=T P D_{>50}$, and use this for the corresponding computations of $A E P=A E P_{>50}$ in Figs. 8. The mesh resolution of $240 \mathrm{~m}$, combined with the 30-arcsecond resolution (equivalent to around $900 \mathrm{~m}$ ) for the bathymetry, gives a better representation of the tidal energy 

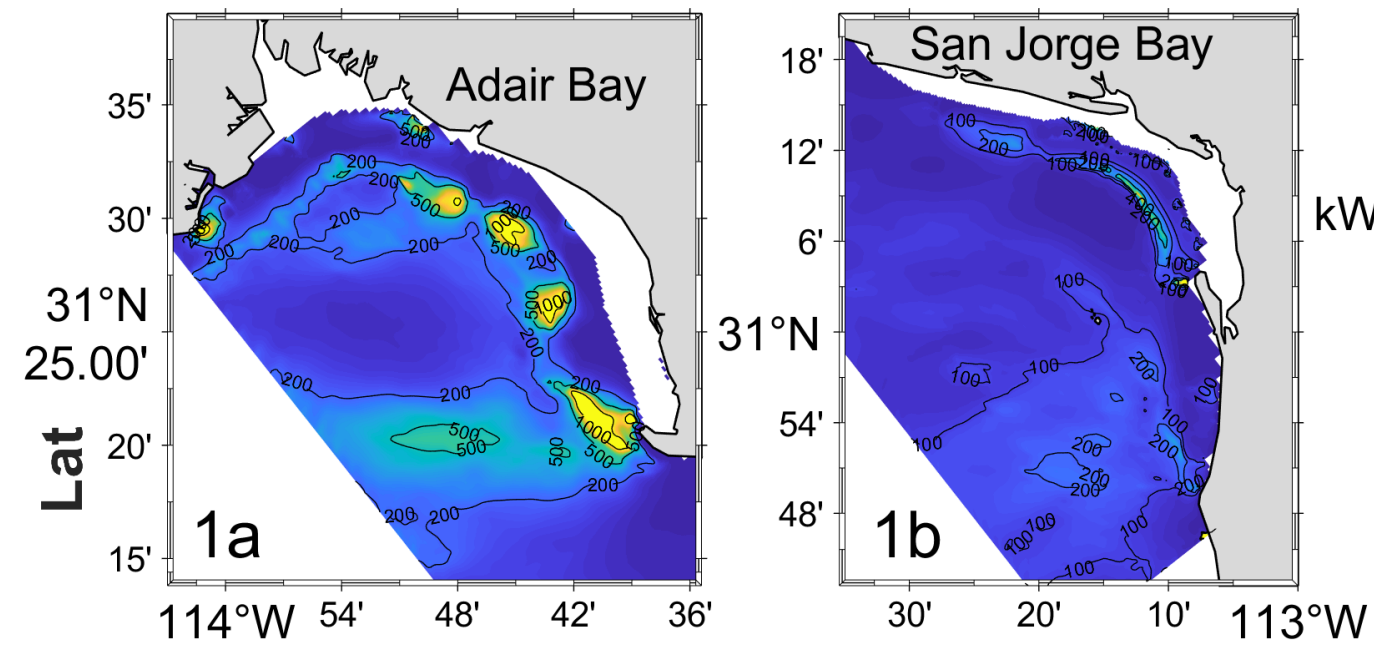

$\mathrm{kWh} / \mathrm{m}^{2}$
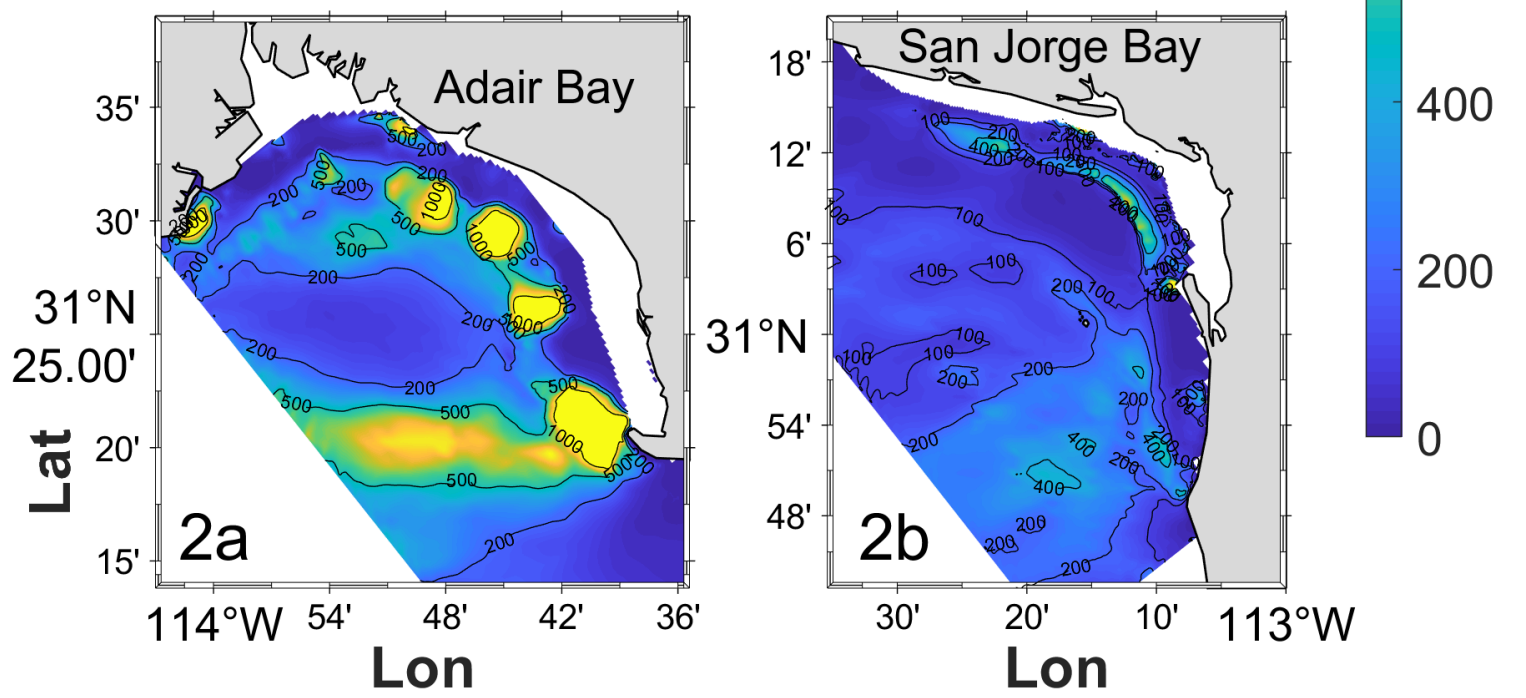

Figure 6. AEP Contours for Adaír Bay (subplots 1a and 2a) and San Jorge Bay (plots $1 \mathrm{~b}$ and 2b) obtained with the GC_MD (subplots $1 \mathrm{a}$ and $1 \mathrm{~b}$ ) and with the GC_MD mor models (subplots $2 \mathrm{a}$ and $2 \mathrm{~b}$ ). 
resources in shallow regions in comparison to the global model used by [26]. However, we observe that the global model (Fig. 5 of [26]) and the GC_MD model (left subplot, or subplot 1, in Fig. 7 in this paper) both show that the northern side of San Jorge Bay, and the nearshore areas in Adaír Bay, do not provide commercially viable conditions for in-stream tidal energy exploitation. Despite this, we can also see some areas with $T P D_{>50}$ over $200 \mathrm{~W} \mathrm{~m}^{-2}$ in Adaír Bay, such as the nearshore area marked as (a) in Figs. 7 and 8, or the area at the southern edge of Adaír Bay marked as (b). Unfortunately, at the observation point $A B$ inside Adaír Bay, we obtained low TPD values and a correspondingly low $A E P$, but this does not affect the use of $A B$ for model validation purposes. The area marked (c) in San Jorge Bay is the only area in this Bay with $T P D_{>50}$ above $200 \mathrm{~W} \mathrm{~m}^{-2}$. As can be seen on the left subplot of Figs. 8, the area (a) has the largest $A E P_{>50}$ of the four marked regions. In fact, at (a) the $A E P$ obtained after one year with the model GC_MD is actually $2245.6 \mathrm{kWh} \mathrm{m}^{-2}$, as shown in Table 3. The only place where such high values of $A E P$ are observed is in the nearshore region of Adaír Bay.
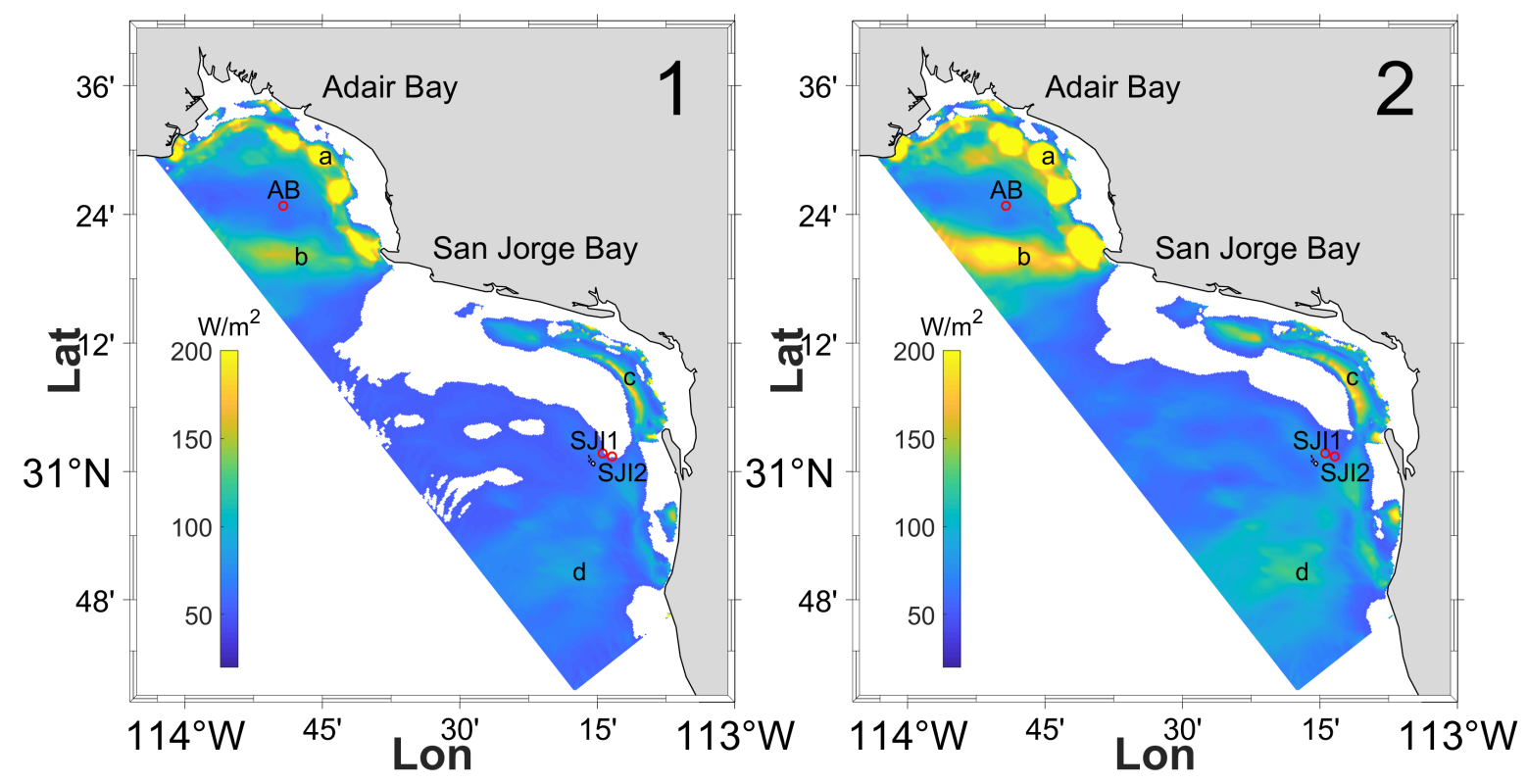

Figure 7. Map of $T P D_{>50}$, corresponding to the yearly mean of $T P D$ when $T P D>50 \mathrm{~W} \mathrm{~m}^{-2}$, obtained with the GC_MD (left, subplot 1) and with the GC_MD mor models (right, subplot 2).

\subsection{Effects of morphological evolution on tidal energy resources}

Figures 7 and 8 show the predicted $T P D_{>50}$ and $A E P_{>50}$ for the GC_MD (on the left) and the GC_MD $D_{\text {mor }}$ (on the right) models. Firstly, we observe that the best locations for in-stream tidal energy exploitation do not shift in space after one year when we have seabed changes (model GC_MD mor results on the right) in comparison to when we have a fixed bathymetry (model GC_MD results on the left). In Adaír Bay, the area covered by these locations increases in the GC_MD $D_{\text {mor }}$ model, which is reassuring as the seabed in this region is naturally mobile, and therefore the $G C \_M D_{\text {mor }}$ predictions are expected to be closer to reality. In contrast, in San Jorge Bay, although we see an increase in in-stream tidal energy resources predicted by GC_MD $\mathrm{D}_{\text {mor }}$ at the locations where the resources were good in GC_MD, the area they cover does not increase in comparison to the area they cover in the GC_MD simulation. Although the resources remain marginally exploitable in both simulations, these analyses indicate that Adaír Bay is a better location than San Jorge Bay for a demonstration in-stream tidal energy site, and its suitability improves when the tides force the seabed to evolve, at least in the first year.

We consider now the percentage of time, $\% T$, when the TPD is equal or above the cut-in TPD of $50 \mathrm{~W} \mathrm{~m}^{-2}$, and evaluate the impact of morphodynamic evolution. Subplots $1 \mathrm{a}$ and $1 \mathrm{~b}$ in Fig. 9 show $\% T$ when TPD is above $50 \mathrm{~W} \mathrm{~m}^{-2}$, for the GC_MD model, and subplots $2 \mathrm{a}$ and $2 \mathrm{~b}$ in Fig. 9 show \% $\mathrm{T}$ 

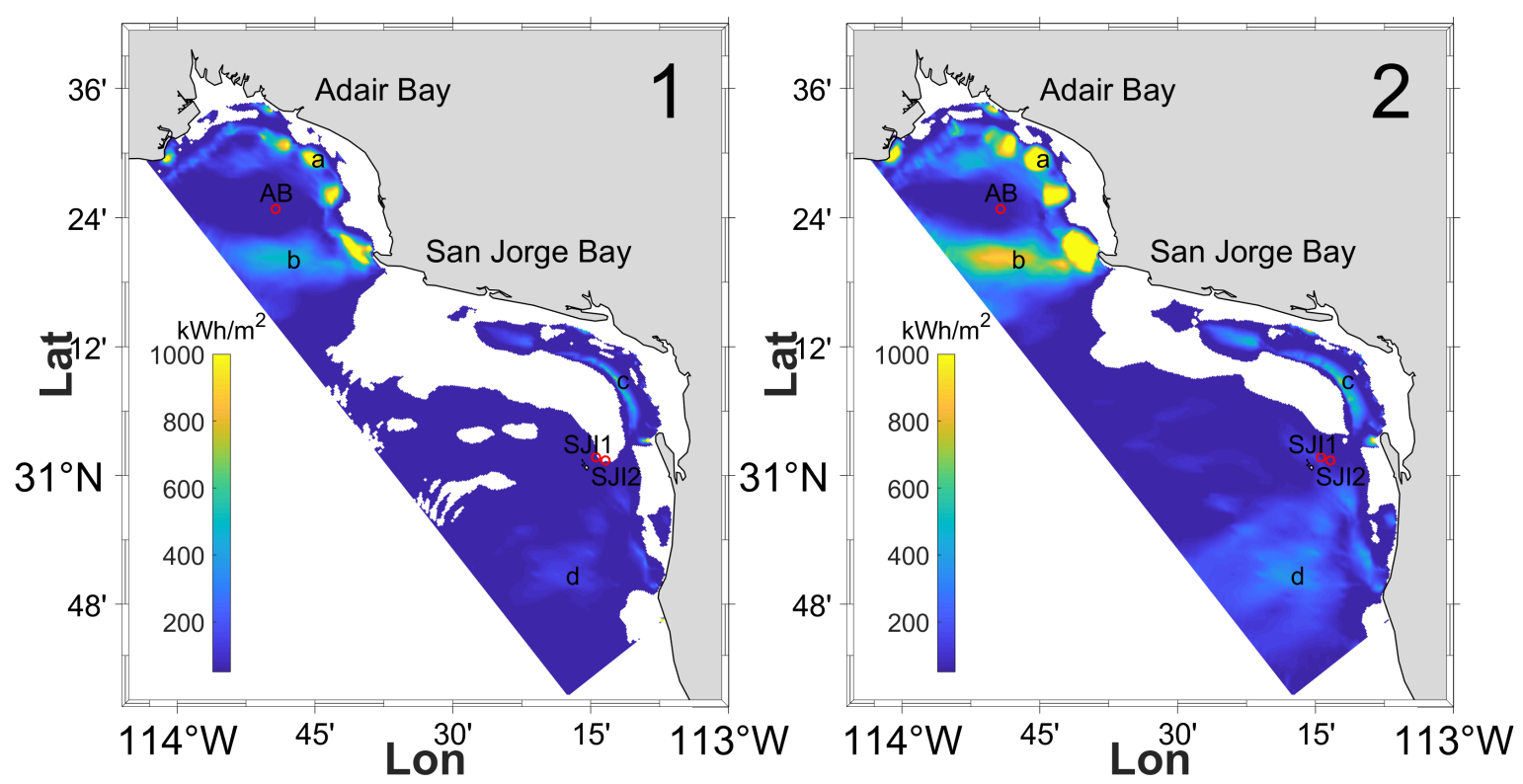

Figure 8. Map of $A E P_{>50}$, corresponding to the annual energy production when only the values of $T P D>50 \mathrm{~W} \mathrm{~m}^{-2}$ are considered, obtained with the GC_MD (left, subplot 1 ) and with the GC_MD mor models (right, subplot 2).

when TPD is above $50 \mathrm{~W} \mathrm{~m}^{-2}$, for the GC_MD $\mathrm{D}_{\text {mor }}$ model. The maps in subplots 1a and 2a show Adaír Bay, where we can identify regions where TPD is above $50 \mathrm{~W} \mathrm{~m}^{-2}$ for more than $40 \%$ of the time, for both for GC_MD and GC_MD mor. There are also vast regions in Adaír Bay where $\% T$ is close to $60 \%$. Figure 9 shows results that are consistent with those in Figs. 7 and 8, obtaining good agreement between areas with the largest $T P D_{>50}$ and $A E P_{>50}$ and areas with the largest $\% T$. We also note that the region along and near the same longitude as that of location (b) (see Fig. 7), is the region with the largest morphological changes near the coast, in particular close to the eastern shore of the bay, but this impact is positive from an in-stream renewable resource perspective. On the other hand, in San Jorge Bay we found that the percentage of time when TPD is above the cut-in value is generally below $40 \%$ (Subplots $1 \mathrm{~b}$ and $2 \mathrm{~b}$ in Fig. 9), and in the GC_MD model (no morphodynamics), the regions satisfying this constraint are quite small (Figure 9, 1b). These results show that the optimal location for tidal energy resource exploitation is near the southeastern corner of Adaír Bay, west of the peninsular hook known locally as "Punta Choya". The results show that when the seabed evolves with time, the regions with high tidal energy potential remain centred in the same locations, but the area they cover spreads and becomes larger within a year. In these regions $\% T$ is between $40 \%$ and $60 \%$, for both GC_MD and GC_MD mor simulations.

We now investigate in more detail the bathymetric changes over one year, and the changes they cause on tidal energy resources. The subplots of Fig. 11 show the difference between final and initial bathymetry for GC_MD mor, while the subplots in Fig. 10 show the evolution over the year of simulation at the locations marked as (a), (b), (c), and (d) in Fig. 11. Table 3 shows $d_{i}$, the water depth for the GC_MD model, which remains unchanged; $d_{f}$, the final water depth at these locations in GC_MD mor, with the initial water depth being the one reported for GC_MD; $A E P$, the $A E P$ obtained with the GC_MD model; and $A E P_{\text {mor }}$, the $A E P$ obtained with the GC_MD mor model.

In the nearshore of Adaír Bay, marked as (a), the change in water depth can be larger than one meter, as can be seen in Fig. 11a. Since the initial water depth here is of the order of $6 \mathrm{~m}$, as shown in Fig. 10a, then the relative change in water depth is between 15 and $25 \%$ in this region. The bathymetry in the nearshore of Adaír Bay consists of a series of sandy shoals, which are flattened over time by the tides. This shoal flattening leads to an increase in water depth (yellow / light grey regions in the nearshore) at the crests of the shoals, and a decrease in water depth on the slopes of the shoals (blue / 

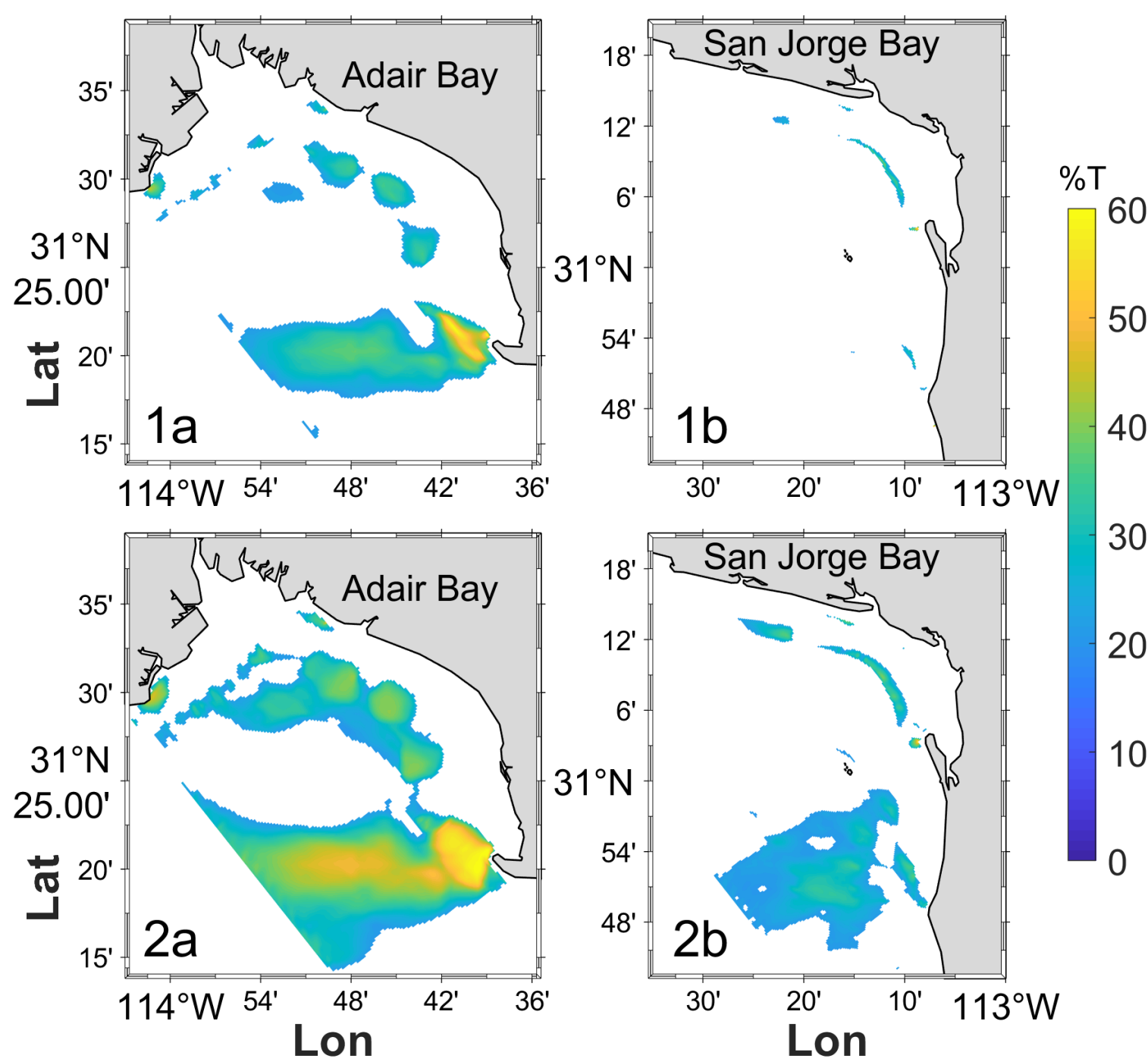

Figure 9. Percentage time, $\% T$, when $T P D$ is above $50 \mathrm{~W} \mathrm{~m}^{-2}$, for Adaír Bay (subplots 1a and 2a) and San Jorge Bay (plots $1 b$ and 2b) obtained with the GC_MD (subplots 1a and 1b) and with the GC_MD mor models (subplots $2 \mathrm{a}$ and $2 \mathrm{~b}$ ).

dark grey regions, adjacent to the yellow / light grey regions previously mentioned). That is, the tides tend to flatten the shoals in the nearshore region, but do not make the shoals migrate. This region is very shallow and perhaps some tidal fences or horizontal Flumill devices could be used for energy exploitation, however they may be exposed at low tide, so the tidal energy plant would have to be an exclusion zone to ship traffic. Implementing an exclusion zone could cause security problems and would reduce the temporal windows for energy generation.

The southern edge of Adaír Bay is the second area that we investigated, marked as (b) in Fig. 11. In this region the relative change in water depth is significantly smaller than in the nearshore area of Adaír Bay, because, as we can see in Table 3 and in Fig. 10b, the initial depth was of $11 \mathrm{~m}$, and the change in water depth after one year was a bit larger than $3 \mathrm{~cm}$. Therefore, the relative water depth change is really small, around $0.3 \%$. Despite this very small relative water depth change, we observe an increase of around $773 \mathrm{kWh} \mathrm{m}^{-2}$ between $A E P$ and $A E P_{\text {mor }}$. Therefore, small bathymetric changes may lead to important changes in $A E P$, as demonstrated by the results at (b).

The third area investigated, marked as (c) in Fig. 11, is the nearshore area of San Jorge Bay. Here we have a small, curved sand ridge that initially increases in size due to sediment feedbacks from the nearshore, but after that the ridge is flattened by the action of the tides. The initial increase in size is 


\begin{tabular}{|l|l|l|l|l|}
\hline Position & $d_{i}[\mathrm{~m}]$ & $d_{f}[\mathrm{~m}]$ & $A E P\left[\mathrm{kWh} \mathrm{m}^{-2}\right]$ & $A E P_{\text {mor }}\left[\mathrm{kWh} \mathrm{m}^{-2}\right]$ \\
\hline a & 5.7 & 7 & 2245.6 & 3019.8 \\
\hline b & 11 & 11.03 & 1116.2 & 1889.5 \\
\hline c & 2.7 & 2.9 & 1668.3 & 1387.4 \\
\hline d & 30.32 & 30.31 & 443.31 & 847.85 \\
\hline
\end{tabular}

Table 3. Bathymetry and AEP in the GC_MD and GC_MD mor models, at the sample locations discussed in the text.

of only $20 \mathrm{~cm}$, and the ridge flattening induced a final bathymetry change from the initial depth of less that $20 \mathrm{~cm}$. As shown in Table 3, the initial water depth is $2.7 \mathrm{~m}$, so here the relative change in water depth between the initial and final bathymetries is of $7.4 \%$. Here the change in AEP between the GC_MD and the GC_MD models is of around $281 \mathrm{kWh} \mathrm{m}^{-2}$, with a decrease in AEP when the mode includes morphodynamics. Finally, it is important to note that this area is possibly too shallow for tidal energy exploitation, except for devices developed specifically for such environments.

Finally, we consider the deep-water region at the southern edge of San Jorge Bay, marked as (d) in Fig. 11. As shown in subplot d) in Fig. 10, the initial water depth here is of $30.32 \mathrm{~m}$, and the bathymetry only changed around $1 \mathrm{~cm}$, so the relative change in water depth is only $0.03 \%$. Despite this, we have an increase in $A E P$ of $200 \mathrm{kWh} \mathrm{m}^{-2}$, in a region where the hydrodynamic model predicted an AEP of around $404.5 \mathrm{kWh} \mathrm{m}^{-2}$ between the GC_MD and the GC_MD models. But since the AEP for the GC_MD model is $443.3 \mathrm{kWh} \mathrm{m}^{-2}$, here actually we have an increase of $100 \%$ in AEP between the morphodynamic model and the hydrodynamic model. The AEP predicted here by both models, however, is much smaller than in the nearshore of Adaír Bay.
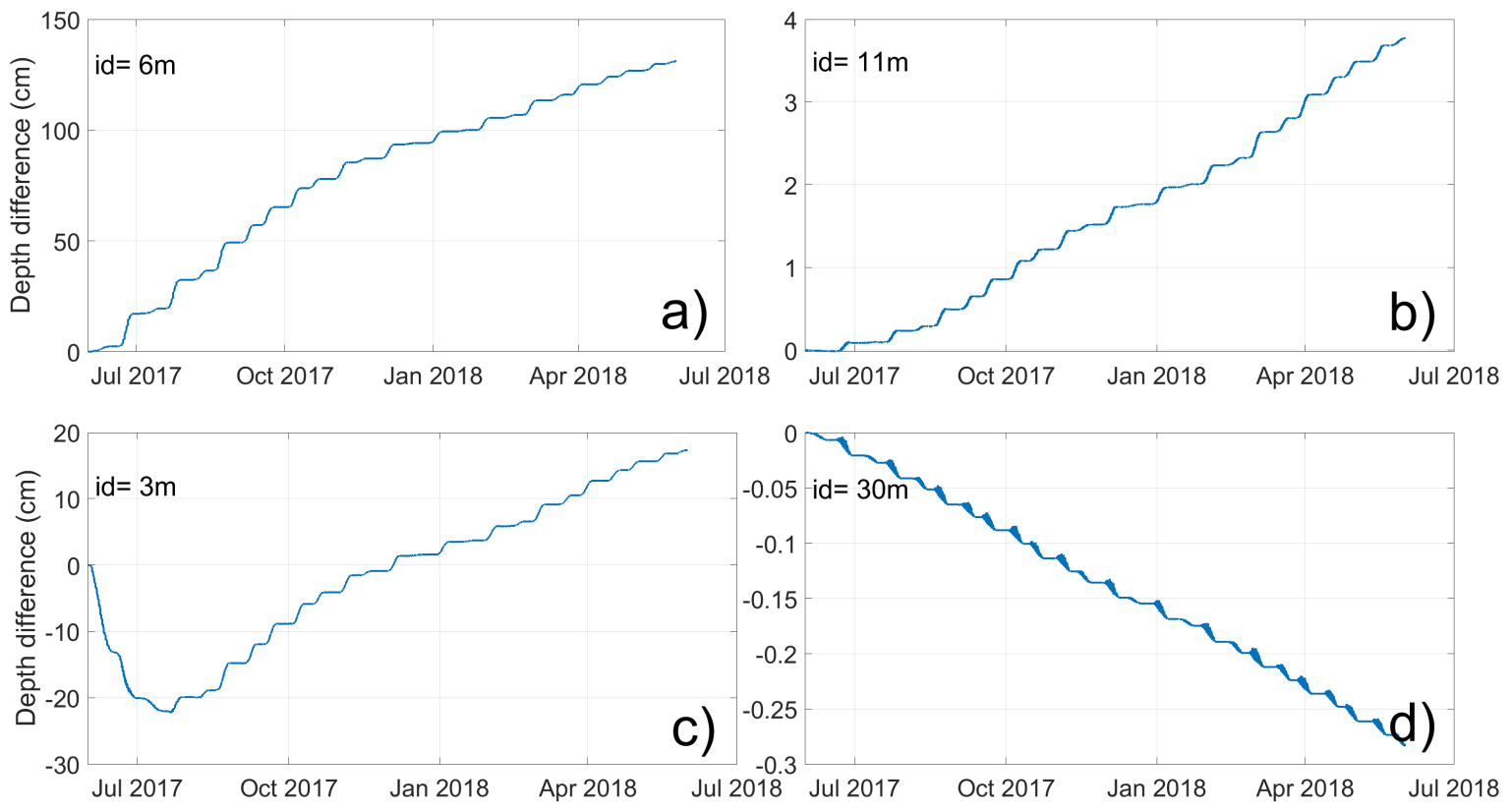

Figure 10. Bathymetric evolution in GC_MD $\mathrm{D}_{\text {mor }}$ after one year of simulation at the locations (a), (b), (c) and (d) marked in the maps of Fig. 11 and Fig. 12. The id number on the northwestern side of the subplots is the initial depth at the location being considered.

We now present some analyses of depth and AEP change pattern maps (Fig. 11 and Fig. 12), after one year of simulations with GC_MD mor over Adaír Bay and San Jorge Bay. We observe a close correlation between regions with large depth changes (Fig. 11) and regions with large AEP changes (Fig. 12), in particular, as before, in areas where the $A E P$ predicted by GC_MD was already large. The largest depth changes are in the nearshore region of Adaír Bay (see Fig. 11a), particularly off Punta Choya (marked on the map of Fig. 12). 

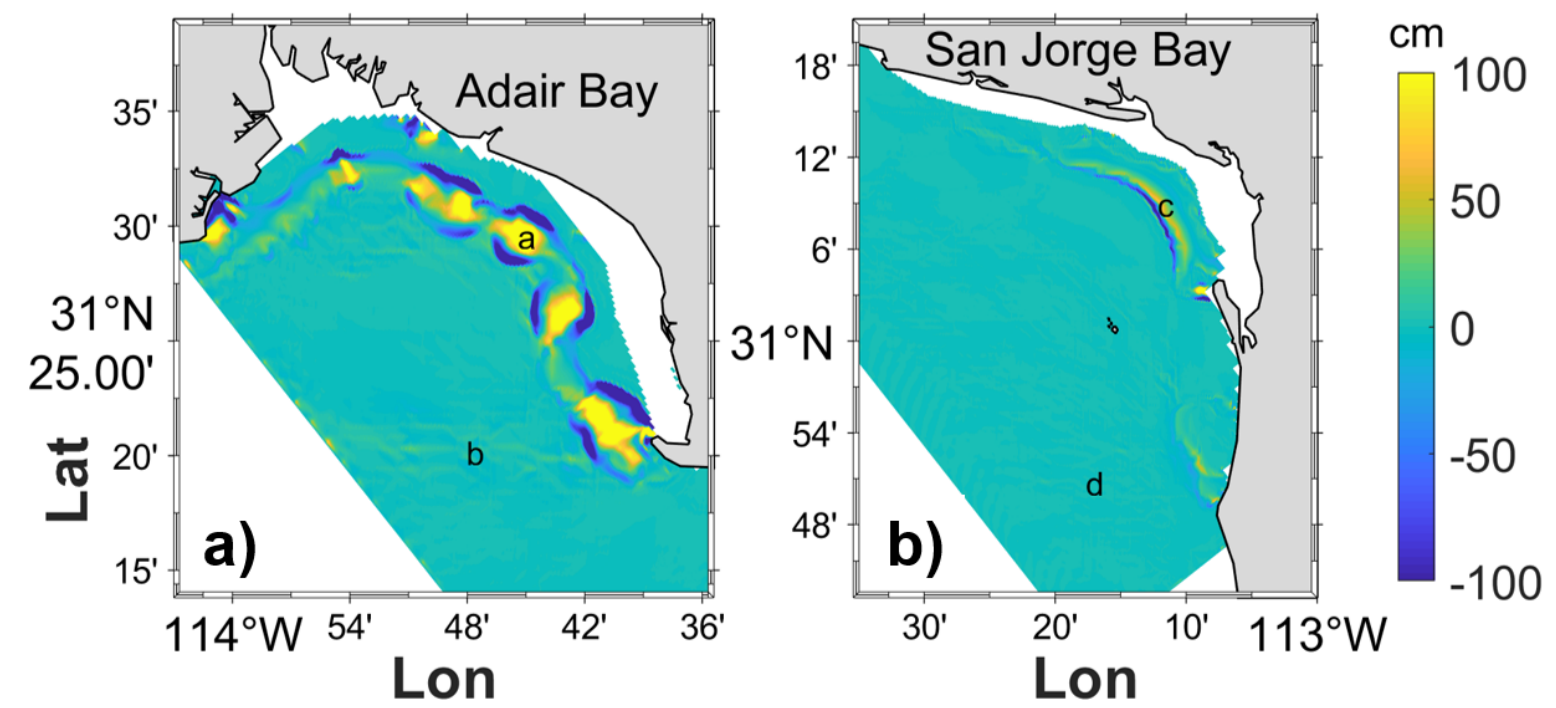

Figure 11. Depth change pattern maps after one year of simulation (GC_MD mor model). Yellow areas: seabed erosion regions, with a depth change of $100 \mathrm{~cm}$ or larger. Blue areas: seabed accretion regions, with a depth change of $-100 \mathrm{~cm}$ or larger. These blue and yellow areas are (a) near the coast of Adaír Bay, mostly on the eastern side of the Bay, and; (b) near the coast of San Jorge Bay, mostly on northeastern and eastern sides of the Bay.

Finally, we now assess the depth changes along a transect across the region with largest $A E P$ changes, which corresponds to a zonal transect off Punta Choya and passing through the area (b) in Fig. 12. Figure 13 shows depth changes as a function of distance to shore after one year and after two years of simulation. The region between 2 and $5 \mathrm{~km}$ from the shoreline is an erosion zone, while the region between 5 and $8 \mathrm{~km}$ from the shoreline is an accretion zone. We also observe a small accretion zone between 11 and $13 \mathrm{~km}$ from the shoreline. The figure shows there is a net seawards migration of sediment over time. The profile is likely to be converging towards an equilibrium profile under the action of the tidal forcing. The equilibrium profile has a slope that is much smaller than that for the equilibrium beach profiles defined by Dean [30] for wave-driven sandy beaches, in line with macrotidal environments such as this one [31].

\section{Conclusions}

In this work we developed three different regional models, one with low spatial resolution and two with high spatial resolution, to assess the likely effects of morphological evolution on tidal energy resources in two macrotidal sandy bays located at the northeastern side of the Upper GC, Mexico. After some initial validations, we discarded the model with low spatial resolution in favour of the two high-resolution models. The high-resolution models had same the forcings, the same parameters, and the same resolution of $240 \mathrm{~m}$ in the two bays, but one of them, the GC_MD model, was purely hydrodynamic, while the GC_MD $\mathrm{D}_{\text {mor }}$ model, was a morphodynamic model. We validated the models using in-situ measurements obtained with three ADCP moorings, with very acceptable results. We used three renewable energy indicators, namely the mean tidal spring flow speed, the tidal power density, and the annual energy production, to characterise the tidal energy resources in the region, and to analyse the effects of depth changes on the annual power production, $A E P$, after one year of simulation. We computed the $A E P$ with the two models, and we found that the regions with the most substantial depth changes in the GC_MD $\mathrm{M}_{\text {mor }}$ simulations are well correlated with the regions where the $A E P$ difference between the GC_MD and the GC_MD mor model predictions is largest. Most of these regions are found near the shore, with the area with most significant changes being west of Punta Choya, on the southeastern corner of Adaír Bay. A closer analysis of the seabed evolution along 


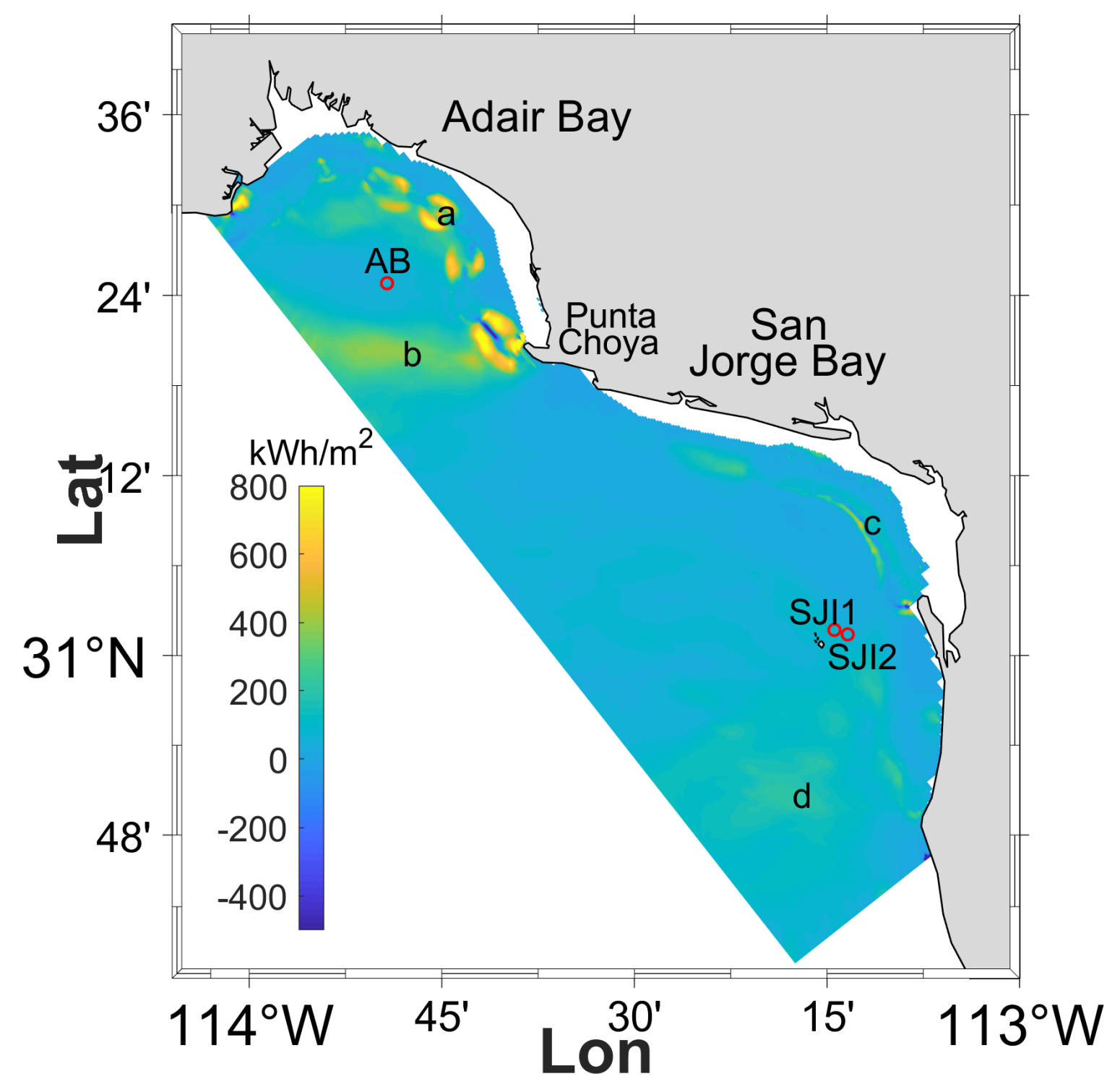

Figure 12. Difference between the $A E P$ obtained in the morphodynamic model GC_MD mor, and the hydrodynamic model, GC_MD, within one year of simulation.

a zonal transect off Punta Choya showed that the seabed is likely to evolve towards an equilibrium profile with a smaller slope than that expected from Dean's for wave-driven beaches. This result is expected, based on the morphological drivers and characteristics of macrotidal, sandy beaches.

Author Contributions: conceptualization, ABR and VM; methodology, ABR; software, ABR and VM; validation, ABR, MLM and VMG; formal analysis, ABR and VM; investigation, ABR and VM; resources, MSG, MLM and JC; data curation, MLM, VMG and MLM; writing-original draft preparation, ABR and VM; writing-review and editing, all authors; visualization, ABR; supervision, VM; project administration, VM.

Funding: This research was partly funded by SENER-CONACYT grant number 249795.

Acknowledgments: Thanks to the Department of Physical Oceanography of CICESE, and in particular technician Erick Rivera-Lemus, for his support with fieldwork and data acquisition. Thanks to the Oceanographic Equipment Coordination and the CANEK group of CICESE, for support with equipment and equipment maintenance resources. Thanks to the anonymous reviewers for their comments.

Conflicts of Interest: The authors declare no conflict of interest. 


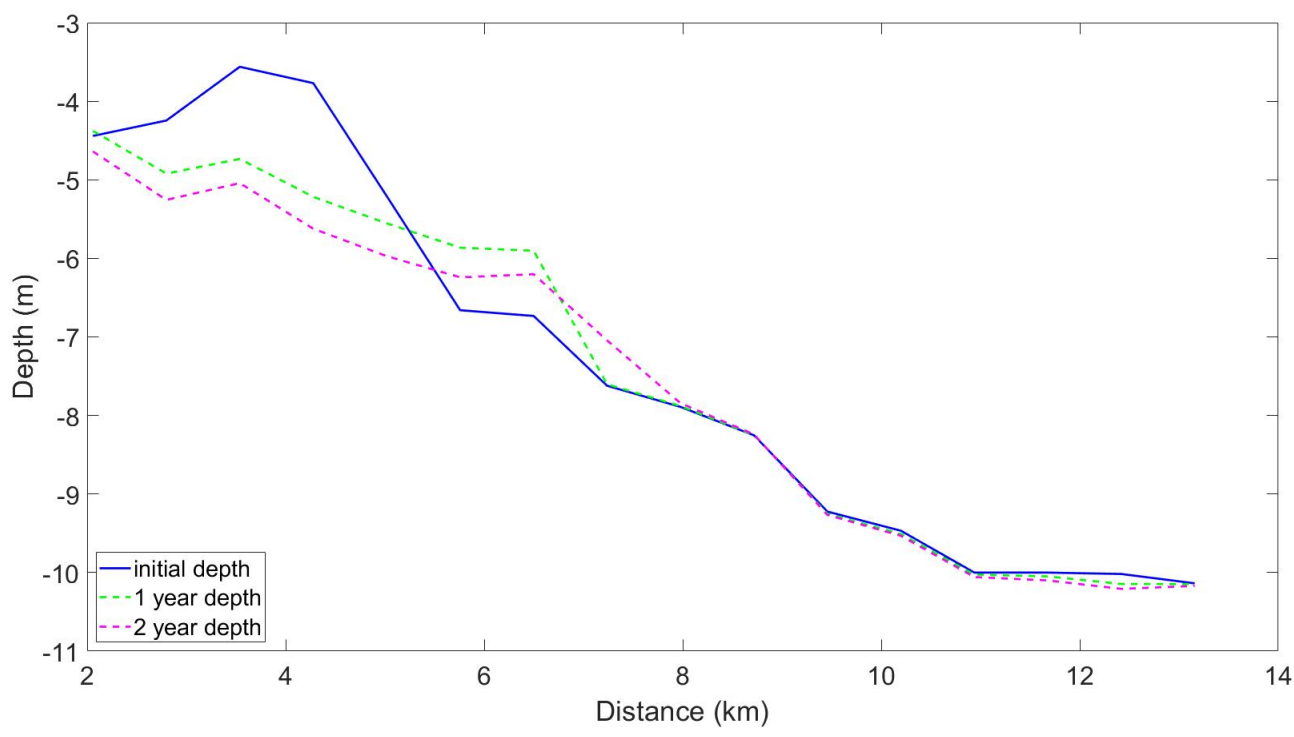

Figure 13. Bathymetric profile along a zonal transect off Punta Choya: initial profile, and evolution after one year and after two years.

\section{References}

1. Gutiérrez, M.O.; López, M.; Candela, J.; Castro, R.; Mascarenhas, A.; Collins, C.A. Effect of coastal-trapped waves and wind on currents and transport in the Gulf of California. Journal of Geophysical Research: Oceans 2014, 119, 5123-5139. doi:10.1002/2013jc009538.

2. Carbajal, N.; Backhaus, J.O. Simulation of tides, residual flow and energy budget in the Gulf of California. Oceanologica Acta 1998, 21, 429-446. doi:10.1016/s0399-1784(98)80028-5.

3. Lluch-Cota, S.E. Coastal upwelling in the eastern Gulf of California. Oceanologica Acta 2000, 23, 731-740. doi:10.1016/s0399-1784(00)00121-3.

4. Marinone, S.G.; Lavín, M.F. Residual Flow and Mixing in the Large Islands Region of the Central Gulf of California. In Nonlinear Processes in Geophysical Fluid Dynamics; Springer Netherlands, 2003; pp. 213-236. doi:10.1007/978-94-010-0074-1_13.

5. Hiriart Le Bert, G. Potencial energético del Alto Golfo de California. Boletín de la Sociedad Geológica Mexicana 2009, 61, 143-146. doi:10.18268/bsgm2009v61n1a13.

6. Magar, V. Tidal Current Technologies. In Sustainable Energy Technologies; CRC Press, 2017; pp. $293-308$. doi:10.1201/9781315269979-18.

7. Lancín, M. Geomorfología y génesis de las flechas litorales del Canal de Infiernillo, Estado de Sonora. Revista del Instituto de Geología, UNAM, 6, 52-72.

8. Bermúdez-Romero, A.; Magar, V.; Gross, M.S.; Godínez, V.M.; López-Mariscal, M.; Rivera-Lemus, E. Characterization of in-stream tidal energy resources in the Gulf of California: implementation, calibration and validation of a hydrodynamic model. Proceedings of the $13^{\text {th }}$ European Wave and Tidal Energy Conference (EWTEC2019), Napoli, Italy, 2019, European Wave and Tidal Energy Conference Series.

9. Haverson, D.; Bacon, J.; Smith, H.C.; Venugopal, V.; Xiao, Q. Modelling the hydrodynamic and morphological impacts of a tidal stream development in Ramsey Sound. Renewable Energy 2018, 126, 876-887. doi:10.1016/j.renene.2018.03.084.

10. Magar, V.; Gross, M.; González-García, L. Offshore wind energy resource assessment under techno-economic and social-ecological constraints. Ocean E Coastal Management 2018, 152, 77-87. doi:10.1016/j.ocecoaman.2017.10.007.

11. Chatzirodou, A.; Karunarathna, H.; Reeve, D.E. 3D modelling of the impacts of in-stream horizontal-axis Tidal Energy Converters (TECs) on offshore sandbank dynamics. Applied Ocean Research 2019, 91, 101882. doi:10.1016/j.apor.2019.101882. 
12. Robins, P.E.; Neill, S.P.; Lewis, M.J. Impact of tidal-stream arrays in relation to the natural variability of sedimentary processes. Renewable Energy 2014, 72, 311-321. doi:10.1016/j.renene.2014.07.037.

13. Gross, M.; Magar, V. Wind-Induced Currents in the Gulf of California from Extreme Events and Their Impact on Tidal Energy Devices. Journal of Marine Science and Engineering 2020, 8, 80. doi:10.3390/jmse8020080.

14. Haverson, D.; Bacon, J.; Smith, H.C.; Venugopal, V.; Xiao, Q. Cumulative impact assessment of tidal stream energy extraction in the Irish Sea. Ocean Engineering 2017, 137, 417-428. doi:10.1016/j.oceaneng.2017.04.003.

15. LeGrand, C. Assessment of Tidal Energy Resource - Marine Renewable Energy Guides. Technical report, Black and Veatch Ltd, London, UK, 2009.

16. Stelling, G.S. On the construction of computational methods for shallow water flow problems. PhD thesis, Applied Sciences, Delft, The Netherlands, 1983.

17. Phillips, N.A. A Coordinate System having some special advantages for numerical forecasting. Journal of Meteorology 1957, 14, 184-185. doi:10.1175/1520-0469(1957)014<0184:acshss>2.0.co;2.

18. Rodi, W. Turbulence models and their application in hydraulics: a state of the art review; The Netherlands: International Association for Hydraulic Research, 1984.

19. Deltares. D-Flow Flexible Mesh User Manual. Deltares, 2020.

20. Egbert, G.D.; Bennett, A.F.; Foreman, M.G.G. TOPEX/POSEIDON tides estimated using a global inverse model. Journal of Geophysical Research 1994, 99, 24821. doi:10.1029/94jc01894.

21. Egbert, G.D.; Erofeeva, S.Y. Efficient Inverse Modeling of Barotropic Ocean Tides. Journal of Atmospheric and Oceanic Technology 2002, 19, 183-204. doi:10.1175/1520-0426(2002)019<0183:eimobo>2.0.co;2.

22. Álvarez, L.G.; Suárez-Vidal, F.; Mendoza-Borunda, R.; González-Escobar, M. Bathymetry and active geological structures in the Upper Gulf of California. Boletin de la Sociedad Geológica Mexicana 2009, 61, 129 141.

23. Van Rijn, L. Principles of Sediment Transport in Rivers, Estuaries and Coastal Seas; Aqua Publications, 1993; p. 715.

24. Baston, S.; Waldman, S.; Side, J., Modelling Extraction in Tidal Flows. In TeraWatt Position Papers - A "toolbox" of methods to better understand and asses the effects of tidal and wave energy arrays on the marine environment.; Marine Alliance for Science and Technology in Scotland, 2015; pp. 75-108.

25. Pearson, K. Mathematical Contributions to the Theory of Evolution. III. Regression, Heredity, and Panmixia. Philosophical Transactions of the Royal Society A: Mathematical, Physical and Engineering Sciences 1896, 187, 253-318. doi:10.1098/rsta.1896.0007.

26. Magar, V.; Godínez, V.M.; Gross, M.S.; López-Mariscal, M.; Bermúdez-Romero, A.; Candela, J.; Zamudio, L. In-Stream Energy by Tidal and Wind-Driven Currents: An Analysis for the Gulf of California. Energies 2020, 13, 1095. doi:10.3390/en13051095.

27. Chen, F. The Kuroshio Power Plant; Springer International Publishing, 2013. doi:10.1007/978-3-319-00822-6.

28. The European Marine Energy Centre, E. Flumill, 2020. Last accessed: 14/11/2020.

29. Minesto. https://www.minesto.com/our-technology, 2019. Last accessed: 19/11/2019.

30. Dean, R.G.; Charles, L. Equilibrium beach profiles: concepts and evaluation. Technical report, University of Florida, Gainesville, FL, USA, 1994.

31. Scott, T.; Masselink, G.; Russell, P. Morphodynamic characteristics and classification of beaches in England and Wales. Marine Geology 2011, 286, 1-20. doi:10.1016/j.margeo.2011.04.004. 